\section{Primary intestinal follicular lymphoma diagnosed by video capsule endoscopy and double-balloon enteroscopy}

A 56-year-old woman presented with a 2year history of large-volume diarrhea. Examination and investigations for diarrhea, palpitations, and flushes in 2004 revealed no abnormalities - in particular, the $\mathrm{H}_{2}$ breath test with lactose and 24hour urinary metanephrine and 5-hydroxyindoleacetic acid (5HIAA) levels were normal. At the time of this recent presentation there were no abnormalities found on physical examination and routine laboratory tests were also normal, including the thyroid-stimulating hormone and the tissue transglutaminase levels; the gastrin level was $65 \mathrm{ng} / \mathrm{L}$ (normal range $0-110 \mathrm{ng} / \mathrm{L}$ ) and the vasoactive intestinal peptide was $<5 \mathrm{ng} / \mathrm{L}$. The fecal weight was $417-1800 \mathrm{~g}$ per 24 hours.

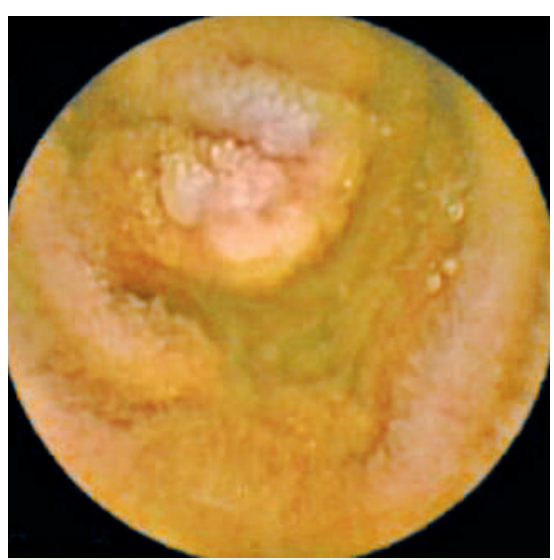

Fig. 1 Video capsule endoscopy (VCE) image of a polypoid lesion in the jejunum.

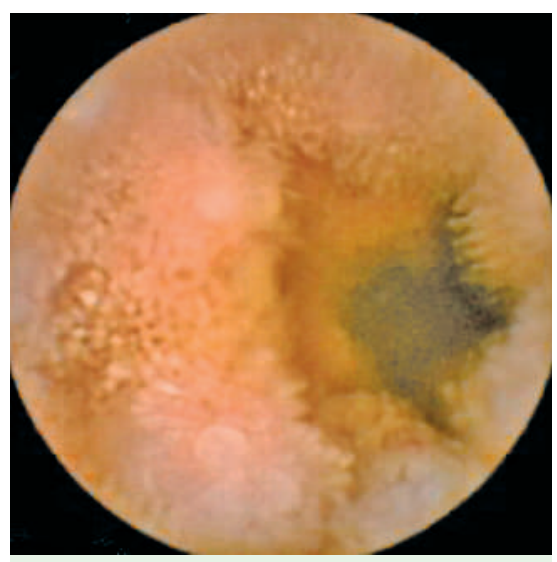

Fig. 2 VCE image of a jejunal lesion.
Duodenoscopy and colonoscopy revealed no abnormalities and histological examination of duodenal and colonic biopsies obtained at these examinations also showed no abnormalities. Video capsule endoscopy was performed and this revealed two polypoid lesions in the jejunum ( Fig. 1, 2). At double-balloon enteroscopy a localized abnormality was identified that looked like lymphoid hyperplasia. Histological examination revealed a monotonous population of lymphoid cells in the lamina propria with a follicular pattern that was positive for Bcell markers CD20 and CD79, and also expressed CD10, Bcl-2, and Bcl-6; CD5 and cyclin-D1 were negative. Monoclonality of the B-cell lymphocytes was demonstrated by a polymerase chain reaction-based rearrangement of the immunoglobulin heavy chain gene. These findings were compatible with a low-grade (grade 1) B-cell follicular lymphoma ( Fig.3-6). Bone marrow examination showed no evidence of non-Hodgkin lymphoma. A diagnosis of diarrhea due to a primary intestinal follicular lymphoma (grade 1) in the jejunum (stage IE) was made.

Video capsule endoscopy and double-balloon enteroscopy are relatively new techniques that provide imaging of the small intestine and which are now used for the diagnosis of a variety of conditions, including obscure gastrointestinal bleeding, Crohn's disease, polyposis syndromes, and celiac disease [1-4]. In celiac disease these techniques can be used to detect the development of enteropathy-associated T-cell lymphoma. They have been used to diagnose other forms of lymphoma, such as B-cell lymphoma of mucosa-associated lymphoid tissue [5], and video capsule endoscopy can also be used as a primary diagnostic tool, as in our case.

To our knowledge (after a PubMed search) this is the first report of a nonHodgkin lymphoma (primary intestinal follicular lymphoma) detected by means of double-balloon enteroscopy.

Endoscopy_UCTN_Code_CCL_1AC_2AC

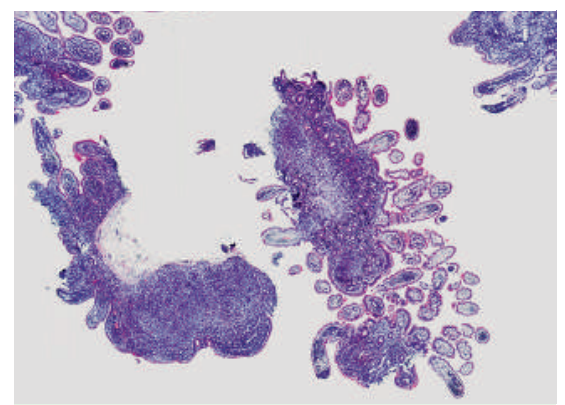

Fig. 3 Histological view showing diffuse and follicular lymphoid infiltration in the intestinal mucosa (hematoxylin and eosin stain, original magnification $\times 40$ ).

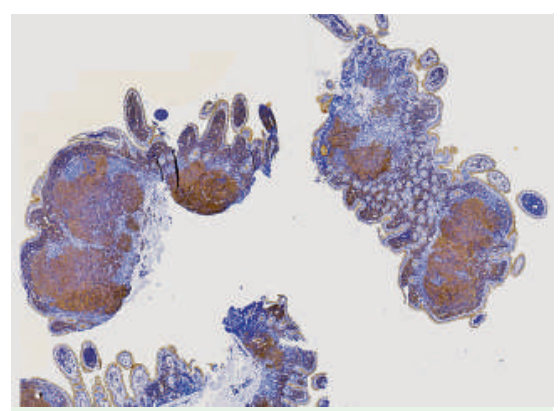

Fig. 4 Immunohistochemical staining for CD10, a marker for B lymphocytes (original magnification $\times 40$ ). The tumor population is seen here to stain positively for this marker.

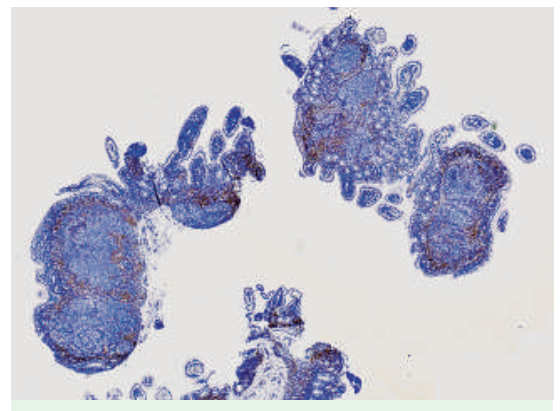

Fig. 5 Immunohistochemical staining for CD5, a marker for T lymphocytes (original magnification $\times 40$ ). The tumor cells are not staining for this marker.

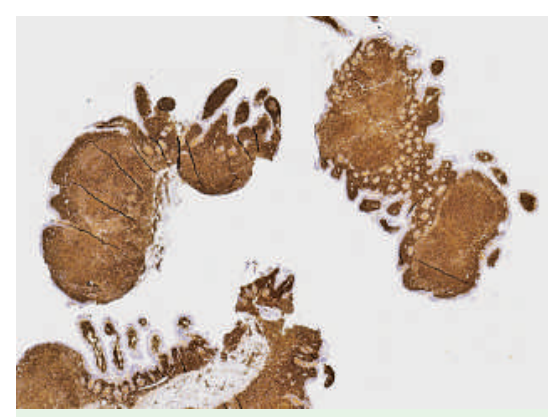

Fig. 6 Immunohistochemical staining for $\mathrm{BCl}-$ 2 (original magnification $\times 40$ ). The neoplastic follicles stain positively and reactive follicles do not stain. 
C. T. B. M. van Deursen ${ }^{1}$, J. G. Goedhard ${ }^{1}$, K.-S. G. Jie ${ }^{1}$, P. Theunissen ${ }^{2}$

${ }^{1}$ Department of Internal Medicine and Gastroenterology, Atrium Medical Center, Heerlen, The Netherlands

2 Department of Clinical Pathology, Atrium Medical Center, Heerlen, The Netherlands

\section{References}

1 Pennazio M. Capsule endoscopy: where are we after 6 years of clinical use? Dig Liver Dis 2006; 12 : 867-878

2 Yamamoto H, Kita H. Double-balloon endoscopy [review]. Curr Opin Gastroenterol 2005; $21: 573-577$

3 Manabe N, Tanaka S, Fukumoto A et al. Double-balloon enteroscopy in patients with $\mathrm{Gl}$ bleeding of obscure origin. Gastrointest Endosc 2006; 64: 135-140

4 Akahoshi K, Kubokawa M, Matsumoto $M$ et al. Double-balloon endoscopy in the diagnosis and management of GI tract diseases: methodology, indications, safety and clinical impact. World J Gastroenterol 2006; 47: 7654-7659

5 Yoshida N, Wakabayashi N, Nomura K et al. Ileal mucosa-associated lymphoid tissue lymphoma showing several ulcer scars detected using double-balloon endoscopy. Endoscopy 2004; 11: $1022-1024$
Bibliography

DOI $10.1055 / s-2007-995379$

Endoscopy 2008; 40: E8 -E9

(c) Georg Thieme Verlag KG Stuttgart · New York . ISSN 0013-726X

Corresponding author

\section{T. B. M. van Deursen, MD, PhD}

Department of Internal Medicine and Gastroenterology

Atrium Medical Center

PO Box 4446

6401 CX Heerlen

The Netherlands

Fax: +31-45-5279477

C.vandeursen@atriummc.nl 